\title{
Diferentes temperaturas e combinações de recipientes e substratos na produção de mudas de mostarda
}

\author{
Ana Régia Alves de Araújo Hendges ${ }^{*}$, Marcelo de Almeida Guimarães ${ }^{2}$, Juliana de Mesquita \\ Camilo², Felipe Rodrigues Costa Feitosa², Celly de Lima Maia $^{2}$
}

\begin{abstract}
RESUMO: Objetivou-se avaliar a germinação de sementes de mostarda em função da temperatura e a emergência e o crescimento das mudas sob diferentes recipientes e substratos. O experimento foi conduzido na Universidade Federal do Ceará, Fortaleza-CE, onde foi dividido em dois ensaios. No primeiro, avaliou-se as temperaturas $(15,20,25,30,35$ e 40 ${ }^{\circ} \mathrm{C}$ ), sob delineamento inteiramente casualizado e com quatro repetições. No segundo, usou-se o delineamento de blocos casualizados, com quatro repetições e sob esquema de parcelas subdividida para a emergência e subsubdividida para o crescimento das mudas. Nas parcelas, avaliou-se os recipientes (450, 200 e 162 células), nas subparcelas, os substratos [S1 - 100\% húmus de minhoca (HM); S2 - 60\% HM, 20\% fibra de coco (FC) e 20\% de vermiculita (VERM); e S3 $80 \%$ (HM), $10 \%$ (FC) e 10\% (VERM) e nas subsubparcelas, as idades das mudas (25, 32 e 42 dias após a semeadura). As temperaturas de 23,3 e $26,6^{\circ} \mathrm{C}$ proporcionaram o maior percentual e velocidade de germinação das sementes, respectivamente. A emergência foi favorecida pelo substrato $\mathrm{S} 3$, enquanto que o maior crescimento das mudas foi obtido no recipiente de 162 células, preenchido com o substrato $\mathrm{S} 1$ e aos 42 dias após a semeadura.
\end{abstract}

Palavras-chave: Brassica juncea spp. integrifolia var. integrifolia, bandejas de polipropileno, húmus de minhoca, crescimento de plântula.

\section{Different temperatures and combinations of containers and substrates in the production of mustard seedlings}

\begin{abstract}
The study aimed to evaluate the germination of mustard seeds in function of temperature and the emergence and development of seedlings under different containers and substrates. The experiment was conducted at the Federal University of Ceará, Fortaleza, Brazil. It was divided into two trials. In the first, temperatures $(15,20,25$, 30,35 and $40^{\circ} \mathrm{C}$ ) were evaluated in a completely randomized design with four replicates. In the second, randomized complete block design was used, with four replications and with split plot scheme for the emergence and with split-split plot scheme for the development of the seedlings. The plot contained the containers $(450,200$ and 162 cells), the split plots the substrates [S1 - 100\% earthworm humus (HM); S2 - 60\% HM, 20\% Coconut fiber (FC) and 20\% vermiculite (VERM); and S3-80\% (HM), 10\% (FC) and 10\% (VERM)] and the split-split plots the seedlings ages (25, 32 and 42 days after sowing). Temperatures of 23.3 and $26.6^{\circ} \mathrm{C}$ provided the highest percentage and speed of germination rate, respectively. The emergence was favored by substrate $\mathrm{S} 3$, whereas the best seedling development was obtained in the container of 162 cells, filled with the substrate S1 and at 42 days after sowing.
\end{abstract}

Keywords: Brassica juncea spp. integrifolia var. integrifolia, polypropylene containers, earthworm compost, seedling growth.

\section{INTRODUÇÃO}

A mostarda (Brassica juncea ssp. integrifolia var. integrifolia), pertencente à família Brassicaceae, é uma hortaliça folhosa ainda pouco difundida no Brasil. Ela é uma planta herbácea, com porte entre 0,3 e 1,6 m de altura, caule não ramificado e folhas de tamanhos e formas diferenciados, com margens serrilhadas e sabor picante, sendo muito apreciadas em saladas (DIXON, 2007).

Segundo o mesmo autor, a cultura adapta-se preferencialmente às condições de temperaturas mais amenas (abaixo de $25^{\circ} \mathrm{C}$ ), mas também se desenvolve em condições ambientais menos favoráveis, como sob altas temperaturas, muito comuns no Norte e Nordeste do Brasil. No entanto, mesmo apresentando bom potencial produtivo, nessas regiões ainda não há relatos de produção e de desenvolvimento de pesquisas que visem o cultivo de mostarda.

Semelhante a outras brássicas, a implantação da mostarda no campo ocorre normalmente por meio do plantio de mudas (FILGUEIRA, 2008). Essa técnica proporciona condições que favorecem o crescimento máximo, permitindo plântulas vigorosas em uma quantidade mínima de tempo (PINTO et al., 2016),

Recebido em 07/04/2018; Aceito para publicação em 27/09/2018

${ }^{1}$ Instituto Federal do Maranhão

${ }^{2}$ Universidade Federal do Ceará

*E-mail: ana.alves@ifma.edu.br 
além de outros benefícios operacionais, tais como economia de insumos, otimização dos tratos culturais e uniformidade de estande (FILGUEIRA, 2008; KANO et al., 2008; MAGRO et al., 2011).

No entanto, o sucesso do cultivo e o desempenho final da cultura da mostarda, assim como estabelecido para outras hortaliças semeadas indiretamente, estão intimamente ligados à qualidade das mudas produzidas (FERREIRA et al., 2014; SOUZA; REZENDE, 2011). Segundo Costa et al. (2011), o alto padrão das mudas representa $60 \%$ do sucesso da cultura no campo.

Diante disso, o conhecimento da tecnologia de produção torna-se essencial (GUIMARÃES et al., 2012), sobretudo quanto às temperaturas (SANTOS et al., 2010), tamanho de recipientes e tipos de substratos mais adequados à espécie durante o estabelecimento das fases iniciais de crescimento (GUERRA et al., 2017). Esses fatores influenciam a velocidade e uniformidade da germinação das sementes (CARVALHO; NAKAGAWA, 2009), determinam o espaço disponível para o crescimento radicular (KANO et al., 2008) e atuam sobre a arquitetura das raízes e o estado nutricional das mudas (TESSARO et al., 2013), respectivamente.

Baseado no exposto, o presente trabalho teve por objetivo avaliar o comportamento germinativo das sementes de mostarda submetidas a diferentes temperaturas e a emergência e crescimento das mudas desta espécie em função de diferentes recipientes e formulações de substratos.

\section{MATERIAL E MÉTODOS}

Foram realizados dois ensaios durante os meses de junho a setembro de 2014, conforme descrito abaixo. O primeiro ensaio foi conduzido no Laboratório de Análises de Sementes e o segundo em ambiente protegido (viveiro) na Horta Didática, ambos pertencentes ao Departamento de Fitotecnia, da Universidade Federal do Ceará, em Fortaleza-CE, Brasil. O clima da região, pela classificação de Köppen, é As (tropical com verão seco) (ALVARES et al., 2014).

\subsection{Ensaio I: Comportamento germinativo das sementes}

$\mathrm{O}$ ensaio foi conduzido em delineamento inteiramente casualizado, com seis tratamentos (temperaturas diurnas de 15, 20, 25, 30, 35 e $40{ }^{\circ} \mathrm{C}$ ) e quatro repetições de 50 sementes. Durante o ensaio, a temperatura noturna permaneceu constante em $25{ }^{\circ} \mathrm{C}$ e com o fotoperíodo de $12 / 12$ horas de luz/escuro.

As sementes de mostarda, cultivar 'Takana Ohba Red Giant', foram distribuídas em placas de Petri com papel filtro umedecido com água destilada, na proporção de 2,5 vezes sua massa seca, e posteriormente, transferidas para incubadoras tipo Biochimical oxigen demand (BOD), reguladas de acordo com cada tratamento. As avaliações foram diárias até o sétimo dia após a instalação, determinando-se o percentual de germinação $(G)$ e o índice de velocidade de germinação (IVG). Considerou-se como germinadas, as sementes que apresentaram protrusão da radícula, em torno de 1 mm (BRASIL, 2009). Já o IVG, foi calculado pela equação proposta por Maguire (1962).

Os resultados foram submetidos à análise de variância e para as diferenças significativas, identificadas pelo teste $\mathrm{F}(\mathrm{p}<0,05)$, foram ajustados modelos de regressão.

\subsection{Ensaio II: Influência de substratos e recipientes na produção de mudas}

$\mathrm{O}$ delineamento experimental adotado foi em blocos casualizados, com quatro repetições. Os tratamentos foram dispostos em esquema de parcela subdividida para a avaliação da emergência e em esquema de parcela subsubdividida para a avaliação do crescimento das mudas. Considerou-se como parcela, os recipientes com volumes diferentes (11, 18 e $31 \mathrm{~cm}^{3}$.célula ${ }^{-1}$, correspondendo às bandejas de polietileno de 450, 200 e 162 células); como subparcelas, as formulações de substratos (S1 $100 \%$ húmus de minhoca (HM); S2 - 60\% HM, 20\% fibra de coco (FC) e $20 \%$ de vermiculita (VERM); e S3 - 80\% (HM), $10 \%$ (FC) e 10\% (VERM)) e nas subsubparcelas, as idades das mudas $(25,32$ e 42 dias após a semeadura). A unidade experimental foi composta de 27 mudas.

Os substratos utilizados no ensaio (S1, S2, S3, respectivamente) apresentaram os seguintes atributos físico-químicos: $\mathrm{pH}$ em $\mathrm{H}_{2} \mathrm{O}=7,9 ; 7,4 ; 7,6$; $\mathrm{MO}=17,07 ; 19,96 ; 19,34 \% ; \mathrm{P}=4893 ; 4844 ; 5195$ mg.kg ${ }^{-1} ; \mathrm{K}=3,1 ; 2,6 ; 2,8$ cmolc. $\mathrm{kg}^{-1} ; \mathrm{Ca}=15,3 ; 13,3$; $14,7 \mathrm{cmol}_{\mathrm{c}} \cdot \mathrm{kg}^{-1} ; \mathrm{Mg}=10,7 ; 16,9 ; 16,9 \mathrm{cmol}_{\mathrm{c}} \cdot \mathrm{kg}^{-1}$; $\mathrm{H}+\mathrm{Al}=0,17 ; 1,98 ; 1,16 \mathrm{cmol}_{\mathrm{c}} \cdot \mathrm{kg}^{-1} ; \mathrm{SB}=39,1 ; 39,1$; $40,6 \% ; \mathrm{T}=39,2 ; 41,1 ; 41,8 \% ; \mathrm{V}=99 ; 95 ; 97 \% ; \mathrm{Pt}$ (espaço poroso $)=53,3 ; 63,3 ; 66,7 \% ;$ DG $($ densidade global $=0,85 ; 0,66 ; 0,78 \mathrm{~g} . \mathrm{cm}^{-3} ;$ CRA (capacidade de retenção de água) $=6,0 ; 6,0 ; 5,7 \%$; EA (espaço de aeração) $=10,0 ; 13,0 ; 14,3 \%$.

A semeadura foi realizada distribuindo-se duas sementes por células. Em seguida, os recipientes foram acondicionados em viveiro. As plantas foram irrigadas por sistema de microaspersão, realizandose duas irrigações diárias (início da manhã e final da tarde), com um período de rega em torno de quatro minutos. O viveiro utilizado foi do tipo telado, com estrutura de madeira, $2,5 \mathrm{~m}$ de pé direito, cobertura e fechamento parcial das laterais com tela de $30 \%$ de sombreamento. Aos dez dias da semeadura foi feito o desbaste, deixando apenas uma planta por célula. 
As variáveis avaliadas foram: percentual de emergência (EMER), índice de velocidade de emergência (IVE), diâmetro do coleto (DC, mm), comprimento da parte aérea (CPA, cm), comprimento do sistema radicular $(\mathrm{CR}, \mathrm{cm})$, massa seca da parte aérea (MSPA) (g.planta $\left.{ }^{-1}\right)$, massa seca do sistema radicular (MSR, g.planta ${ }^{-1}$ ) e índice de qualidade de Dickson (IQD). Nas avaliações, foram coletadas aleatoriamente cinco plântulas em cada subparcela.

A emergência foi avaliada diariamente, até a estabilização (sétimo dia após a semeadura), considerando-se emersas, as plântulas com cotilédones expandidos e acima do substrato. O índice de velocidade de emergência foi calculado conforme fórmula adaptada de Maguire (1962).

$\mathrm{O}$ diâmetro do coleto foi determinado na base do caule, com o auxílio de paquímetro digital, enquanto que para a medição do comprimento da parte aérea e da raiz, utilizou-se uma régua graduada em milímetros. A fim de obter a massa seca, as plantas foram seccionadas no coleto, separando-se raiz e parte aérea; e, em seguida, esses materiais foram levados à estufa de circulação forçada de ar à temperatura de $65 \pm 5^{\circ} \mathrm{C}$, onde permaneceram até a obtenção de massa seca constante (cerca de $48 \mathrm{~h}$ ), quando foram pesados em balança de precisão de $0,001 \mathrm{~g}$.

O índice de qualidade de Dickson foi calculado conforme a equação de Dickson et al. (1960) (Equação 1):

$$
\mathrm{IQD}=\frac{\mathrm{MST}}{(\mathrm{RAD}+\mathrm{RPAR})}(\text { Equação } 1)
$$

em que: $\mathrm{MST}=$ massa seca total da planta $(\mathrm{g}) ; \mathrm{RAD}$ = relação da altura da parte aérea com diâmetro do coleto $\left(\mathrm{cm} . \mathrm{mm}^{-1}\right)$; RPAR: relação da massa seca da parte aérea com as raízes $\left(\mathrm{g} \cdot \mathrm{g}^{-1}\right)$.

Os dados foram submetidos à análise de variância e as médias, quando significativas, comparação pelo teste de Scott-Knott ao nível de 5\% de significância.

\section{RESULTADOS E DISCUSSÃO}

\section{Ensaio I: Comportamento germinativo das sementes}

A temperatura teve efeito significativo sobre o percentual e velocidade de germinação das sementes

de mostarda $(p>0,01)$. Para as duas variáveis, a mostarda apresentou comportamento quadrático em função do aumento da temperatura. A maior taxa de germinação foi observada na temperatura de $23,3{ }^{\circ} \mathrm{C}$ (Figura 1A), enquanto que na temperatura de $26,6^{\circ} \mathrm{C}$ a germinação das sementes ocorreu de forma mais rápida (Figura $1 \mathrm{~B}$ ).

Em estudos com sementes de brócolos (Brassica oleracea L. var. italica Plenk), Mauri et al. (2010) observaram que a temperatura de $25^{\circ} \mathrm{C}$ proporcionou maior percentual de germinação das sementes. Ainda considerando espécies da família Brassicaceae, pesquisadores identificaram as temperaturas de 15 e $20{ }^{\circ} \mathrm{C}$ para Thlaspi caerulescens J. Presl \& C. Presl (GUIMARÃES et al., 2010) e de 25 e $30{ }^{\circ} \mathrm{C}$ para crambe (Crambe abyssinica Hochst) (PILAU et al., 2012) como aquelas capazes de promover o máximo percental e índice de velocidade de germinação. Já para a rúcula (Eruca sativa Miller), Steiner et al. (2010) verificaram germinação satisfatória numa faixa mais ampla de temperatura, de 10 a $35^{\circ} \mathrm{C}$.

Por outro lado, quando submetidas a temperaturas acima de $30{ }^{\circ} \mathrm{C}$, as sementes tiveram uma redução na capacidade e velocidade de germinação. Aos $40{ }^{\circ} \mathrm{C}$, a redução foi de $23,8 \%$ para o percentual e de $73,9 \%$ para a velocidade, quando comparados com os valores observados nas temperaturas ótimas. Esses resultados indicam que em temperaturas acima de $30^{\circ} \mathrm{C}$, as sementes passam por estresse, com redução do seu potencial fisiológico. Temperaturas superiores àquelas que ocorrem dentro da faixa considerada ótima, promovem a desnaturação de proteínas, o que afeta os processos bioquímicos envolvidos na germinação. Diante disso, o percentual, uniformidade e a velocidade do processo germinativo das sementes fica limitado (DOUSSEAU et al., 2008). 

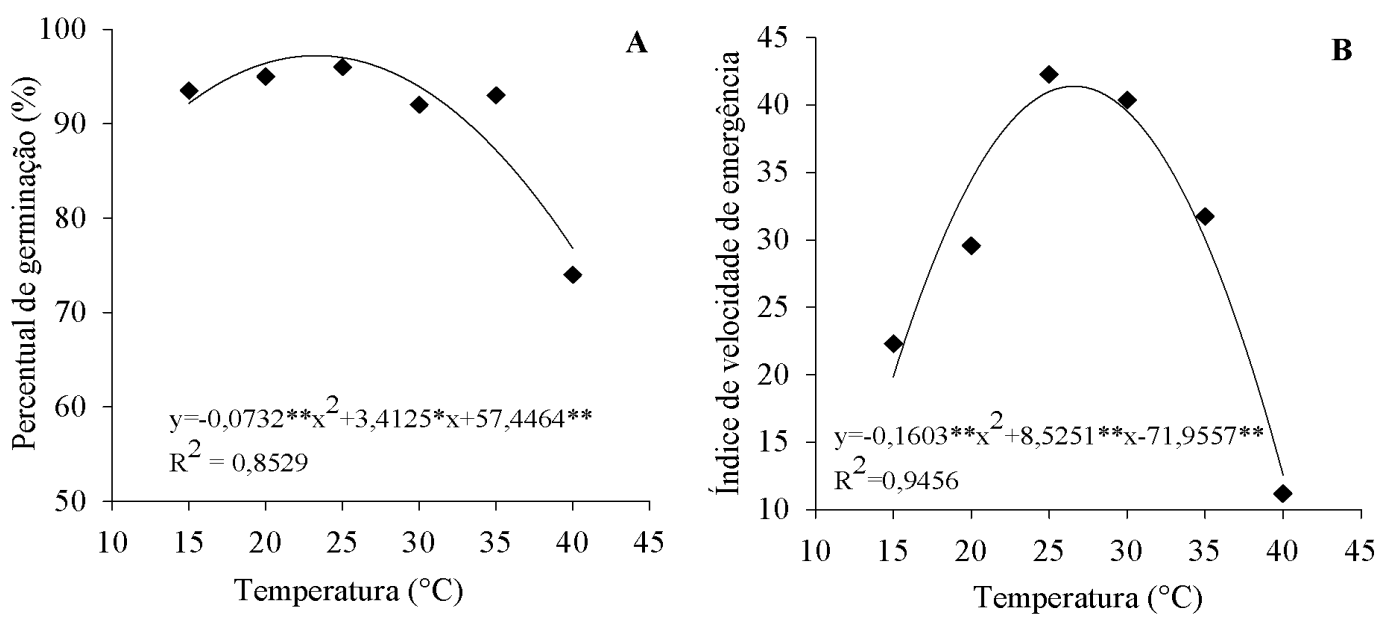

Figura 1. Comportamento germinativo das sementes de mostarda em função da temperatura. (A) Percentual de germinação. (B) Índice de velocidade de germinação.

\section{Ensaio II: Influência de substratos e recipientes na produção de mudas}

Houve interação significativa entre os recipientes e substratos dentro das variáveis estudadas $(\mathrm{p}<0,01)$ (Tabela 1). O recipiente de 162 células, quando preenchido com o substrato S2, apresentou o maior percentual de emergência, enquanto que no recipiente de 200 células, essa característica foi superior quando preenchido com os substratos $\mathrm{S} 2 \mathrm{e}$ S3. Já no estudo dos substratos, observa-se que o S1, independente do recipiente utilizado, promoveu uma redução significativa na emergência das plântulas de mostarda.

Para o índice de velocidade de emergência, obteve-se valores intermediários no recipiente de 162 de células, utilizando-se qualquer um dos substratos. Na comparação dos substratos, observouse que as plântulas cultivadas no S2, apresentaram uma emergência mais rápida, independentemente do recipiente, mas sendo semelhante ao S3 no recipiente de 200 células. A emergência tornou-se mais lenta quando as plântulas foram submetidas ao substrato $\mathrm{S} 1$
Os efeitos diferenciados dos substratos na emergência das plântulas de mostarda podem estar relacionados com suas características físicoquímicas, sendo que o tipo e a quantidade de material presentes na composição podem alterá-las. Nesse sentido, a alta concentração de húmus de minhoca foi a responsável pela maior densidade $\left(0,85 \mathrm{~g} \cdot \mathrm{cm}^{-3}\right)$ e menor espaço poroso $(53,5 \%)$ do substrato $\mathrm{S} 1$ em comparação aos demais, o que provavelmente colaborou para que as plântulas emergissem mais lentamente, devido a maior resistência oferecida pelo substrato.

Por outro lado, o melhor desempenho dos substratos S2 e S3 na emergência, podem indicar um efeito positivo da adição de materiais condicionantes, tais como a fibra de coco e vermiculita. Esses materiais contribuíram para a melhor aeração do substrato, e com isso, obtendo as maiores taxa e velocidade de emergência. Substratos com baixa densidade apresentam maior porosidade, melhor drenagem e menor restrição física ao crescimento e desenvolvimento das plântulas (MAGGIONI et al., 2014).

Tabela 1. Percentual de emergência (EMER) e índice de velocidade de emergência (IVE) de plântulas de mostarda em função do recipiente e substrato.

\begin{tabular}{|c|c|c|c|c|c|c|}
\hline \multirow{2}{*}{ Substratos } & \multicolumn{3}{|c|}{ EMER (\%) } & \multicolumn{3}{|c|}{ IVE } \\
\hline & 450 & 200 & 162 & 450 & 200 & 162 \\
\hline $\mathrm{S} 1^{1}$ & $5,93 \mathrm{Cb}$ & $5,56 \mathrm{Cb}$ & $25,51 \mathrm{Ca}$ & $1,71 \mathrm{Cb}$ & $0,92 \mathrm{Bb}$ & $4,54 \mathrm{Ca}$ \\
\hline S2 & $62,72 \mathrm{Bb}$ & 76,11 Aa & $82,71 \mathrm{Aa}$ & $21,44 \mathrm{Aa}$ & $18,85 \mathrm{Aa}$ & 19,64 Aa \\
\hline S3 & $50,74 \mathrm{Ab}$ & $78,89 \mathrm{Aa}$ & $70,99 \mathrm{Ba}$ & $15,65 \mathrm{Bb}$ & $20,68 \mathrm{Aa}$ & $16,00 \mathrm{Bb}$ \\
\hline Média & & 47,04 & & & 11,98 & \\
\hline CV $1(\%)$ & & 13,14 & & & 17,42 & \\
\hline CV $2(\%)$ & & 10,25 & & & 13,57 & \\
\hline
\end{tabular}

Médias seguidas pelo menos uma letra igual, minúscula nas linhas e maiúsculas nas colunas, não diferem entre si pelo teste de Scott-Knott $(\mathrm{p}<0,05)$.

${ }^{1}$ S1 (100\% húmus de minhoca); S2 (80\% húmus de minhoca e 20\% fibra de coco); S2 (60\% húmus de minhoca, $20 \%$ fibra de coco e $20 \%$ vermiculita) e S3 (80\% húmus de minhoca, $10 \%$ fibra de coco e $10 \%$ vermiculita). 
Com relação ao crescimento das mudas, verificou-se que a interação entre recipientes, substratos e idades das mudas ocasionou efeito significativo $(p<0,05)$ sobre o diâmetro do coleto, comprimento da parte aérea e do sistema radicular e índice de qualidade de Dickson (Tabela 2). A massa seca da parte aérea foi influenciada $(\mathrm{p}<0,05)$ pela interação entre recipientes e substratos e entre recipientes e idades das mudas, enquanto que para a massa seca das raízes, observou-se efeito significativo apenas na interação recipiente e idade das mudas $(\mathrm{p}<0,05)($ Tabela 4 e 5).

No desdobramento da interação tripla (recipiente dentro de cada combinação entre substrato e idade das mudas) verificou-se que, de modo geral, o recipiente de 200 células, independentemente do substrato, resultou em mudas com os maiores diâmetros do coleto aos 25 dias após a semeadura (DAS). Com o passar do tempo essa variável continuou sendo favorecida pelos recipientes com maiores volumes de células, sendo que aos 42 DAS, os melhores resultados foram obtidos nos recipientes de 162 e 200 células associados aos substratos S1 e S3, respectivamente. Em estudos realizados por Costa et al. (2017), o recipiente de maior volume também proporcionou melhor condição para o crescimento secundário do caule de mudas de couve de manteiga (Brassica oleracea var. acephala).

No que se refere ao comprimento da parte aérea, observou-se que a combinação do recipiente de 162 células com o substrato $\mathrm{S} 2$ e do recipiente de 450 células preenchido com o substrato S3 obtiveram os melhores desempenhos aos 25 DAS. Enquanto que para o comprimento radicular, os melhores resultados foram obtidos nos recipientes de 200 e de 162 células, preenchidos com S1 e S2, respectivamente. Já os melhores resultados obtidos aos 45 DAS para o comprimento da parte aérea e da raiz, encontram-se em mudas submetidas aos recipientes de 162 e 200 células (Tabela 2).

Reghin et al. (2003) estudando pack choi (Brassica chinensis L.) também demonstraram que recipientes com maiores células produziram mudas com maior comprimento de parte aérea e de raiz em comparação aos recipientes com menor volume de células. Tais resultados podem ser explicados pela influência positiva que o volume de recipiente exerce sobre o desenvolvimento das mudas, em decorrência da maior disponibilidade de espaço físico passível de ser explorado, nutrientes e água.

Quanto aos substratos, observou-se um comportamento variável para os parâmetros diâmetro do colo, comprimento da parte aérea e das raízes, de acordo com o recipiente utilizado. No entanto, pode-se observar que em mudas mais velhas, os substratos com as maiores densidades (S1 e S3) apresentaram os melhores desempenhos nos recipientes de 162 células. Segundo Fermino (2002) em recipientes menores, o substrato deve ser menos denso, pois nessa condição, a dinâmica da movimentação da água (drenagem) e o crescimento radicular não são prejudicados.

Tabela 2. Diâmetro do coleto (DC), comprimento da parte aérea (CPA) e comprimento do sistema radicular (CR) de plântulas de mostarda em função do recipiente e substrato, em cada idade das mudas (dias após a semeadura).

\begin{tabular}{|c|c|c|c|c|c|c|c|c|c|c|}
\hline \multirow{3}{*}{ Idade } & \multirow{3}{*}{ Subst. } & \multicolumn{3}{|c|}{$\mathrm{DC}$} & \multicolumn{3}{|c|}{$\mathrm{CPA}(\mathrm{cm})$} & \multicolumn{3}{|c|}{$\mathrm{CR}(\mathrm{cm})$} \\
\hline & & \multicolumn{9}{|c|}{ Recipiente } \\
\hline & & 450 & 200 & 162 & 450 & 200 & 162 & 450 & 200 & 162 \\
\hline \multirow{3}{*}{25} & $\mathrm{~S} 1^{1}$ & $1,08 \mathrm{Ab}$ & $1,19 \mathrm{Aa}$ & $0,56 \mathrm{Cc}$ & $0,85 \mathrm{Ba}$ & $0,83 \mathrm{Ba}$ & $0,80 \mathrm{Ca}$ & $4,91 \mathrm{Cc}$ & $12,41 \mathrm{Aa}$ & $9,33 \mathrm{Bb}$ \\
\hline & $\mathrm{S} 2$ & 1,04 Aa & $1,11 \mathrm{Ba}$ & $0,93 \mathrm{Bb}$ & $0,99 \mathrm{Ab}$ & $0,73 \mathrm{Bc}$ & 1,39 Aa & $7,28 \mathrm{Ac}$ & $9,87 \mathrm{Bb}$ & $12,74 \mathrm{Aa}$ \\
\hline & S3 & $1,08 \mathrm{Ab}$ & $1,21 \mathrm{Aa}$ & $1,03 \mathrm{Ab}$ & $1,06 \mathrm{Aa}$ & $0,91 \mathrm{Ab}$ & $1,08 \mathrm{Ba}$ & $6,22 \mathrm{Bc}$ & $10,17 \mathrm{Ba}$ & $8,35 \mathrm{Cb}$ \\
\hline \multirow{3}{*}{32} & S1 & $0,91 \mathrm{Ab}$ & $0,96 \mathrm{Ab}$ & $1,05 \mathrm{Aa}$ & $0,98 \mathrm{Bb}$ & 1,19Aa & $0,86 \mathrm{Bb}$ & $6,98 \mathrm{Ab}$ & $10,16 \mathrm{Ba}$ & $7,17 \mathrm{Bb}$ \\
\hline & $\mathrm{S} 2$ & $0,80 \mathrm{Bb}$ & $1,01 \mathrm{Ab}$ & $1,06 \mathrm{Aa}$ & $1,16 \mathrm{Aa}$ & $0,93 \mathrm{Bb}$ & $1,03 \mathrm{Ab}$ & $6,47 \mathrm{Ac}$ & $11,59 \mathrm{Ab}$ & $13,40 \mathrm{Aa}$ \\
\hline & S3 & $0.85 \mathrm{Bb}$ & $1,04 \mathrm{Aa}$ & $1,08 \mathrm{Aa}$ & $0,91 \mathrm{Ba}$ & $1,00 \mathrm{Ba}$ & $1,00 \mathrm{Aa}$ & $6,76 \mathrm{Ac}$ & $10,11 \mathrm{Bb}$ & $13,34 \mathrm{Aa}$ \\
\hline \multirow{3}{*}{42} & S1 & $0,90 \mathrm{Ac}$ & $1,20 \mathrm{Bb}$ & $1,45 \mathrm{Aa}$ & $0,85 \mathrm{Bb}$ & $0,93 \mathrm{Bb}$ & $1,21 \mathrm{Aa}$ & $9,50 \mathrm{Bc}$ & $10,50 \mathrm{Cb}$ & $13,05 \mathrm{Aa}$ \\
\hline & S2 & $0,83 \mathrm{Ac}$ & $1,10 \mathrm{Cb}$ & $1,28 \mathrm{Ba}$ & $1,06 \mathrm{Ab}$ & $1,29 \mathrm{Aa}$ & $1,13 \mathrm{Ab}$ & $11,55 \mathrm{Ac}$ & $13,90 \mathrm{Aa}$ & $12,35 \mathrm{Bb}$ \\
\hline & S3 & $0,87 \mathrm{Ab}$ & $1,30 \mathrm{Aa}$ & $1,27 \mathrm{Ba}$ & $0,83 \mathrm{Bb}$ & $1,21 \mathrm{Aa}$ & $1,26 \mathrm{Aa}$ & $9,27 \mathrm{Bc}$ & $13,15 \mathrm{Bb}$ & $13,69 \mathrm{Aa}$ \\
\hline \multicolumn{2}{|c|}{ Média } & \multicolumn{3}{|c|}{1,046} & \multicolumn{3}{|c|}{1,02} & \multicolumn{3}{|c|}{10,16} \\
\hline \multicolumn{2}{|c|}{ CV $1(\%)$} & \multicolumn{3}{|c|}{4,82} & \multicolumn{3}{|c|}{8,68} & \multicolumn{3}{|c|}{3,83} \\
\hline \multicolumn{2}{|c|}{ CV $2(\%)$} & \multicolumn{3}{|c|}{9,01} & \multicolumn{3}{|c|}{10,57} & \multicolumn{3}{|c|}{6,67} \\
\hline \multicolumn{2}{|c|}{ CV $3(\%)$} & \multicolumn{3}{|c|}{5,45} & \multicolumn{3}{|c|}{8,33} & \multicolumn{3}{|c|}{3,62} \\
\hline
\end{tabular}

Médias seguidas pela mesma letra minúscula não diferem entre si pelo teste $\operatorname{Scott}-\operatorname{Knott}(\mathrm{p}<0,05)$.

${ }^{1}$ S1 (100\% húmus de minhoca); S2 (80\% húmus de minhoca e 20\% fibra de coco); S2 (60\% húmus de minhoca, $20 \%$ fibra de coco e $20 \%$ vermiculita) e S3 ( $80 \%$ húmus de minhoca, $10 \%$ fibra de coco e $10 \%$ vermiculita). 
Já no desdobramento entre idades das mudas e substratos, em cada recipiente (Tabela 3), observouse que houve incrementos no diâmetro do coleto ao longo do tempo para o recipiente de 162 células, com maiores valores aos $42 \mathrm{DAS}$, diferentemente do recipiente de 450 células, que obteve maiores diâmetros do coleto aos 25 DAS. Isso mostra que no cultivo de mudas em recipientes menores, a restrição do volume explorável pelas raízes imposta mais cedo reflete no menor crescimento das mudas.

Para os parâmetros comprimento da parte aérea e da raiz, incrementos crescentes também foram observados nos recipientes com maior volume, 162 células (preenchido com S1 e S3) e 200 células (preenchido com S2 e S3). Nesse caso, as maiores médias foram observadas nas mudas mais velhas (42 DAS), o que indica a otimização do crescimento das mudas em decorrência do maior espaço e fornecimento de nutrientes, nesses recipientes.

Diante desses resultados, fica evidente que a idade ideal para o transplantio das mudas varia em função do volume do recipiente, sendo que em volumes menores as mudas são transplantadas mais precocemente, enquanto que em maiores volumes pode-se estender o período no viveiro. Todavia, segundo Magro et al. (2011), é necessário o estudo do desenvolvimento das mudas até o final do ciclo, a fim de conhecer a influência da idade das mudas sobre a produção.

Tabela 3. Diâmetro do coleto (DC), comprimento da parte aérea (CPA) e comprimento do sistema radicular (CR) de plântulas de mostarda em função das idades das mudas e substratos, em cada recipiente.

\begin{tabular}{|c|c|c|c|c|c|c|c|c|c|c|}
\hline \multirow{3}{*}{ Recip. } & \multirow{3}{*}{ Subst. } & \multicolumn{3}{|c|}{$\mathrm{DC}$} & \multicolumn{3}{|c|}{$\mathrm{CPA}(\mathrm{cm})$} & \multicolumn{3}{|c|}{$\mathrm{CR}(\mathrm{cm})$} \\
\hline & & & & & \multicolumn{3}{|c|}{ Dias } & & & \\
\hline & & 25 & 32 & 42 & 25 & 32 & 42 & 25 & 32 & 42 \\
\hline \multirow{3}{*}{450} & $\mathrm{~S} 1^{1}$ & $1,08 \mathrm{a}$ & $0,92 \mathrm{~b}$ & $0,90 \mathrm{~b}$ & $0,85 \mathrm{~b}$ & $0,98 \mathrm{a}$ & $0,85 \mathrm{~b}$ & $4,91 \mathrm{c}$ & $6,98 \mathrm{~b}$ & $9,50 \mathrm{a}$ \\
\hline & S2 & $1,04 \mathrm{a}$ & $0,80 \mathrm{~b}$ & $0,84 \mathrm{~b}$ & $0,99 \mathrm{~b}$ & $1,16 \mathrm{a}$ & $1,06 \mathrm{~b}$ & $7,28 \mathrm{~b}$ & $6,47 \mathrm{c}$ & $11,55 \mathrm{a}$ \\
\hline & S3 & $1,08 \mathrm{a}$ & $0,85 \mathrm{~b}$ & $0,87 \mathrm{~b}$ & $1,06 \mathrm{a}$ & $0,91 \mathrm{~b}$ & $0,83 \mathrm{~b}$ & $6,22 c$ & $6,76 b$ & $9,27 \mathrm{a}$ \\
\hline \multirow{3}{*}{200} & S1 & $1,19 \mathrm{a}$ & $0,95 \mathrm{~b}$ & $1,20 \mathrm{a}$ & $0,83 \mathrm{~b}$ & $1,19 \mathrm{a}$ & $0,93 \mathrm{~b}$ & $12,41 \mathrm{a}$ & $10,16 \mathrm{~b}$ & $10,50 \mathrm{~b}$ \\
\hline & S2 & $1,11 \mathrm{a}$ & $1,01 \mathrm{~b}$ & $1,10 \mathrm{a}$ & $0,73 \mathrm{c}$ & $0,94 \mathrm{~b}$ & $1,00 \mathrm{a}$ & $9,87 \mathrm{c}$ & $11,59 \mathrm{~b}$ & $13,90 \mathrm{a}$ \\
\hline & S3 & $1,21 \mathrm{~b}$ & $1,04 \mathrm{c}$ & $1,30 \mathrm{a}$ & $0,91 \mathrm{~b}$ & $1,00 \mathrm{~b}$ & $1,21 \mathrm{a}$ & $10,16 \mathrm{~b}$ & $10,11 \mathrm{~b}$ & $13,15 \mathrm{a}$ \\
\hline \multirow{3}{*}{162} & S1 & $0,56 \mathrm{c}$ & $1,05 \mathrm{~b}$ & $1,45 \mathrm{a}$ & $0,80 \mathrm{~b}$ & $0,86 \mathrm{~b}$ & $1,21 \mathrm{a}$ & $9,33 \mathrm{~b}$ & $7,17 \mathrm{c}$ & $13,05 \mathrm{a}$ \\
\hline & S2 & $0,93 \mathrm{c}$ & $1,06 \mathrm{~b}$ & $1,28 \mathrm{a}$ & $1,39 \mathrm{a}$ & $1,03 \mathrm{~b}$ & $1,13 \mathrm{~b}$ & $12,74 \mathrm{~b}$ & $13,40 \mathrm{a}$ & $12,35 \mathrm{a}$ \\
\hline & S3 & $1,03 \mathrm{~b}$ & $1,08 \mathrm{~b}$ & $1,27 \mathrm{a}$ & $1,08 \mathrm{~b}$ & $1,00 \mathrm{~b}$ & $1,26 \mathrm{a}$ & $8,35 \mathrm{~b}$ & $13,34 \mathrm{a}$ & $13,69 \mathrm{a}$ \\
\hline \multicolumn{2}{|c|}{ Média } & \multicolumn{3}{|c|}{1,046} & \multicolumn{3}{|c|}{1,02} & \multicolumn{3}{|c|}{10,16} \\
\hline \multicolumn{2}{|c|}{ CV $1(\%)$} & \multicolumn{3}{|c|}{4,82} & \multicolumn{3}{|c|}{8,68} & \multicolumn{3}{|c|}{3,83} \\
\hline \multicolumn{2}{|c|}{ CV $2(\%)$} & \multicolumn{3}{|c|}{9,01} & \multicolumn{3}{|c|}{10,57} & \multicolumn{3}{|c|}{6,67} \\
\hline \multicolumn{2}{|c|}{ CV $3(\%)$} & \multicolumn{3}{|c|}{5,45} & \multicolumn{3}{|c|}{8,33} & \multicolumn{3}{|c|}{3,62} \\
\hline
\end{tabular}

Médias seguidas pela mesma letra não diferem entre si pelo teste Scott - Knott $(\mathrm{p}<0,05)$.

${ }^{1} \mathrm{~S} 1(100 \%$ húmus de minhoca); S2 (80\% húmus de minhoca e $20 \%$ fibra de coco); S2 (60\% húmus de minhoca, $20 \%$ fibra de coco e $20 \%$ vermiculita) e S3 ( $80 \%$ húmus de minhoca, $10 \%$ fibra de coco e $10 \%$ vermiculita).

Nas Tabelas 4 e 5 são apresentados, respectivamente, os efeitos da interação duplas entre recipiente e substrato e entre recipiente e idade das mudas para as variáveis massa seca da parte aérea e do sistema radicular.

Os maiores valores para a massa seca da parte aérea foram observados em mudas cultivadas em recipiente de 162 células, independentemente do substrato utilizando, porém não se diferindo do recipiente de 200 células quando associado com o substrato S1 (Tabela 4). Costa et al. (2017) também observaram maiores médias de massa seca da parte aérea e radicular quando mudas de couve manteiga foram cultivadas em recipiente de maior volume de célula. De acordo com Filgueira (2008), quanto mais biomassa seca acumulada mais resistente às condições adversas tende a ser a muda, o que permite maior sobrevivência no campo, bem como crescimento inicial no período após o transplantio.

Tabela 4. Massa seca da parte aérea (MSPA) de mudas de mostarda em função de recipientes e substratos.

\begin{tabular}{cccc}
\hline \multirow{2}{*}{ Substratos } & \multicolumn{3}{c}{ Recipientes } \\
\cline { 2 - 4 } & 450 & 200 & 162 \\
\hline $\mathrm{S}^{1}$ & $0,017 \mathrm{Ab}$ & $0,032 \mathrm{Aa}$ & $0,033 \mathrm{Aa}$ \\
\hline
\end{tabular}




\begin{tabular}{rrrr}
\hline S2 & $0,012 \mathrm{Ac}$ & $0,019 \mathrm{Bb}$ & $0,032 \mathrm{Aa}$ \\
S3 & $0,018 \mathrm{Ac}$ & $0,031 \mathrm{Ab}$ & $0,038 \mathrm{Aa}$ \\
\hline Média & 0,025 & & \\
\hline CV 1 $(\%)$ & 9,26 & & \\
\hline CV 2 $(\%)$ & 28,65 & & \\
\hline CV 3 $(\%)$ & 25,07 & & \\
\hline
\end{tabular}

Médias seguidas de pelo menos uma letra igual, minúscula nas linhas e maiúscula nas colunas, não diferem entre si pelo teste Scott - Knott $(\mathrm{p}<0,05)$.

${ }^{1} \mathrm{~S} 1$ (100\% húmus de minhoca); S2 (60\% húmus de minhoca, $20 \%$ fibra de coco e $20 \%$ vermiculita) e S3 ( $80 \%$ húmus de minhoca, $10 \%$ fibra de coco e $10 \%$ vermiculita).

Analisando-se a interação entre recipiente e idade, verifica-se que os acúmulos máximos de biomassa na parte aérea e nas raízes ocorreram aos 42 DAS, sobretudo quando as mudas foram cultivadas nos recipientes de 162 células (Tabela 5). Tais resultados também podem ser explicados a partir da maior disponibilidade de espaço e nutrientes nos recipientes maiores, favorecendo o crescimento do sistema radicular e consequentemente dando suporte ao crescimento da parte aérea; o que reflete em maior acúmulo de biomassa em mudas mais velhas. Com isso, as mais velhas tendem a ser mais resistentes nas condições de campo, desde que apresentem bom desenvolvimento radicular.

Tabela 5. Massa seca da parte aérea (MSPA) e massa seca do sistema radicular (MSR) de mudas de mostarda em função de recipientes e idades das mudas (dias após a semeadura).

\begin{tabular}{|c|c|c|c|c|c|c|}
\hline \multirow{3}{*}{$\begin{array}{l}\text { Idade das } \\
\text { mudas }\end{array}$} & \multicolumn{3}{|c|}{ MSPA (g.planta ${ }^{-1}$ ) } & \multicolumn{3}{|c|}{ MSR (g.planta ${ }^{-1}$ ) } \\
\hline & \multicolumn{6}{|c|}{ Recipientes } \\
\hline & 450 & 200 & 162 & 450 & 200 & 162 \\
\hline 25 & $0,011 \mathrm{Ba}$ & $0,015 \mathrm{Ca}$ & $0,017 \mathrm{Ca}$ & $0,004 \mathrm{Bb}$ & $0,009 \mathrm{Ca}$ & $0,011 \mathrm{Ca}$ \\
\hline 32 & $0,017 \mathrm{Ac}$ & $0,026 \mathrm{Bb}$ & $0,032 \mathrm{Ba}$ & $0,006 \mathrm{Ac}$ & $0,013 \mathrm{Bb}$ & $0,017 \mathrm{Ba}$ \\
\hline 42 & 0,019 Ac & $0,039 \mathrm{Ab}$ & $0,054 \mathrm{Aa}$ & 0,008 Ac & $0,017 \mathrm{Ab}$ & $0,027 \mathrm{Aa}$ \\
\hline Média & 0,025 & & & 0,013 & & \\
\hline CV $1(\%)$ & 9,26 & & & 18,52 & & \\
\hline CV $2(\%)$ & 28,65 & & & 27,55 & & \\
\hline CV $3(\%)$ & 25,07 & & & 26,61 & & \\
\hline
\end{tabular}

Médias seguidas de pelo menos uma letra igual, minúscula nas linhas e maiúscula nas colunas, não diferem entre si pelo teste $\operatorname{Scott}-$ Knott $(\mathrm{p}<0,05)$.

Para o índice de qualidade de Dickson, observouse que não houve diferença proporcionada pelos substratos aos 25 e 32 DAS, enquanto que em mudas mais velhas, o substrato $\mathrm{S} 1$ foi responsável pela obtenção de mudas de maior qualidade, quando aliado ao recipiente de 162 células (Tabela 6). Conforme já relatado descrito por Silva et al. (2007) em estudos com a produção de mudas de couvemanteiga, o uso de substratos com uma concentração de $100 \%$ de húmus de minhoca contribui para um suprimento nutricional (como de cálcio e potássio) mais equilibrado e por mais tempo.

Em relação aos recipientes, apenas o de 162 células conseguiu manter efeito positivo sobre a qualidade das mudas durante todo o período de avaliação, sendo que aos 25 dias após a semeadura ele não se diferiu do recipiente de 200 células, porém mantendo-se superior aos demais recipientes nas idades posteriores, atingindo o índice de qualidade máximo aos 42 dias. Considerando que o IQD traz informações reais sobre a qualidade das mudas, relacionando o acúmulo total de biomassa e a sua distribuição nas diferentes partes da plântula, tais resultados estabelecem a combinação do recipiente de 162 células com o substrato $\mathrm{S} 1$ como a mais indicada para a produção de mudas de mostarda, podendo ser transplantadas para o campo, ao final de um período de 42 dias.

Tabela 6. Índice de qualidade de Dickson (IQD) em função dos recipientes e dos substratos, em cada idade das mudas (dias após a semeadura), e das datas de avalições e substratos, em cada recipiente

\begin{tabular}{|c|c|c|c|c|c|c|c|c|c|}
\hline \multirow{2}{*}{ Idade } & \multirow{2}{*}{ Subst. } & \multicolumn{3}{|c|}{ Recipiente } & \multirow{2}{*}{ Recip. } & \multirow{2}{*}{ Subst. } & \multicolumn{3}{|c|}{ Data } \\
\hline & & 450 & 200 & 162 & & & 25 & 32 & 42 \\
\hline \multirow{3}{*}{25} & $\mathrm{~S} 1^{1}$ & $0,02 \mathrm{Ab}$ & $0,08 \mathrm{Aa}$ & $0,08 \mathrm{Aa}$ & \multirow{3}{*}{450} & $\mathrm{~S} 1^{1}$ & $0,02 \mathrm{a}$ & $0,06 \mathrm{a}$ & $0,05 \mathrm{a}$ \\
\hline & $\mathrm{S} 2$ & $0,04 \mathrm{Ab}$ & $0,11 \mathrm{Aa}$ & $0,11 \mathrm{Aa}$ & & S2 & $0,04 \mathrm{a}$ & $0,04 \mathrm{a}$ & $0,06 \mathrm{a}$ \\
\hline & S3 & $0,04 \mathrm{Ab}$ & 0,12 Aa & $0,10 \mathrm{Aa}$ & & S3 & $0,04 \mathrm{a}$ & $0,05 \mathrm{a}$ & $0,07 \mathrm{a}$ \\
\hline
\end{tabular}




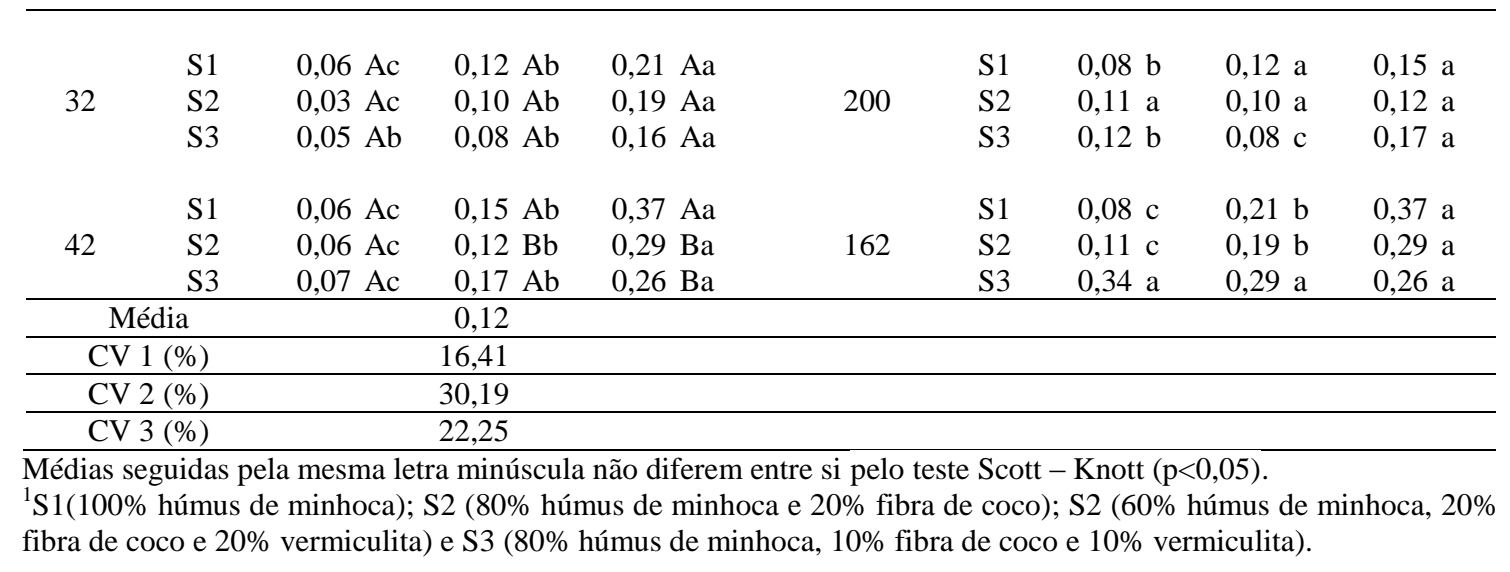

\section{CONCLUSÕES}

1. As temperaturas entre 23,3 e $26,6^{\circ} \mathrm{C}$ foram as mais favoráveis para a germinação das sementes de mostarda.

2. O recipiente de 162 células condicionou o melhor crescimento das plântulas, com incrementos no diâmetro do colo, comprimento e massa fresca e seca da parte aérea e da raiz.

3. O uso de substrato na proporção de $60 \%$ húmus de minhoca associada com $20 \%$ fibra de coco e $20 \%$ vermiculita (S2) favoreceu a emergência das mudas, enquanto que a máxima concentração de húmus de minhoca (S1) contribuiu para a melhor qualidade de mudas aos 42 DAS.

\section{AGRADECIMENTOS}

À UFC pelo suporte técnico que possibilitou a realização da pesquisa. Ao CNPq e a Funcap pelas bolsas fomentadas aos pesquisadores.

\section{REFERÊNCIAS}

ALVARES, C. A.; STAPE, J. L.; SENTELHAS, P. C.; GONÇALVES, J. L. M.; SPAROVEK, G. Köppen's climate classification map for Brazil. Meteorologische Zeitschrift, Stuttgart, v. 22, n. 6, p. 711-728, 2014.

BRASIL. Regras para análises de sementes. Ministério da Agricultura, Pecuária e Abastecimento - MAPA. Secretaria de Defesa Agropecuária. Brasília: Mapa/ACS, 2009. 399 p.

CARVALHO, N. M.; NAKAGAWA, J. Sementes: ciência, tecnologia e produção. 5 ed. Jaboticabal, FUNEP, 2009. 588p.

COSTA, E.; CURI, T. M. R. C.; FIGUEIREDO, T.; BINOTTI, F. F. S.; CARDOSO, E. D. Produção de mudas de couve manteiga em diferentes substratos, volumes de células e ambientes protegidos. Revista Engenharia Agrícola, v. 37, n.1, p. 46-53, 2017.

COSTA, M. R. S.; LEITE, D. T.; QUEIROGA, V. P. P.; LOPES, K. P.; COSTA, C.C. Desenvolvimento de mudas de couve em diferentes substratos e idade. Informativo Técnico do Semi-Árido, Pombal, v. 4, p. 01-06, 2011.

DICKSON, A.; LEAF, A. L.; HOSNER, J. F. Quality appraisal of white spruce and white pine seedling stock in nurseries. Forest Chronicle, v. 36, n. 1, p. 10-13, 1960.

DIXON, G. R. Vegetable brassicas and related crucifers. London: Cab International Nort Amarican Office, 2007. 327p.

DOUSSEAU, S.; ALVARENGA, A. A.; ARANTES, L. O.; OLIVEIRA, D.; NERY, F. C. Germinação de sementes de tanchagem (Plantago tomentosa Lam.): influência da temperatura, luz e substrato. Ciência e Agrotecnologia, Lavras, v. 32, n. 2, p. 438-443, 2008.

FERMINO, M. H. O uso da análise física na avaliação da qualidade de componentes e substratos. In: FURLANI, A. M. C.; BTAGLIA, O. C.; ABREU, M. F.; FURLANI, P. R.; MINAMI, J. A. Q. K. (Coords.). Caracterização, manejo e qualidade de substratos para a produção de plantas. Campinas: Instituto Agronômico. 2002. p.29-37.

FERREIRA, L. L.; ALMEIDA, A. E. S.; COSTA, L. R.; MEDEIROS, J. F.; PORTO, V. C. N. Vermicompostos como substrato na produção de mudas de tomate (Lycopersicon esculentum) e couve-folha (Brassica oleracea var. acephala). Revista Verde de Agroecologia e Desenvolvimento Sustentável, Pombal, v. 9, n. 2, p. 256-263, 2014.

FILGUEIRA, F.A.R. Novo manual de olericultura: agrotecnologia moderna na produção e comercialização de hortaliças. 3 ed. Viçosa: UFV, 2008. $421 \mathrm{p}$.

GUERRA, M. S.; BARBOSA, M. S.; COSTA, E.; VIEIRA, G. H. C. Recipiente biodegradável e substratos para mudas de maracujazeiro. Revista de Agricultura Neotropical, Cassilândia, v. 4, n. 3, p. 50-54, 2017.

GUIMARÃES, M. A.; VIDIGAL, D. S.; LOUREIRO, M. E.; DIAS, D. C. F. S.; GUIMARÃES, A. R. Influência de temperatura, luz e giberelina na germinação de sementes de Thlaspi caerulescens J. Presl \& C. Presl 
(Brassicaceae). Revista Ceres, Viçosa, v. 57, n.3, p. 372376, 2010.

GUIMARÃES, M. A; GARCIA, M. F. N.; DAMASCENO, L. A.; VIANA, C. S. Production of cocona and jurubeba seedlings in different types of containers. Horticultura Brasileira, Brasília, v. 30, n. 4, p. $720-725,2012$.

KANO, C.; GODOY, A. R.; HIGUTI, A. R. O.; CASTRO, M. M.; CARDOSO, A. I. I. Produção de couve-brócolo em função do tipo de bandeja e idade das mudas. Ciência e Agrotecnologia, Lavras, v. 32, n.1, p. 110-114, 2008.

MAGGIONI, M. S.; ROSA, C. B. C. J.; ROSA JUNIOR, E. J.; SILVA, E. F.; ROSA, Y. B. C. J.; SCALON, S. P. Q.; VASCONCELOS, A. A. Desenvolvimento de mudas de manjericão (Ocimum basilicum L.) em função do recipiente e do tipo e densidade de substratos. Revista Brasileira de Plantas Medicinais, Campinas, v.16, n.1, p.10-17, 2014.

MAGRO, F. O.; SALATA, A. C.; BERTOLINI, E. V.; CARDOSO, A. I. I. Produção de repolho em função da idade das mudas. Revista Agro-ambiente On-line, Boa Vista, v. 5, n. 2, p. 119-123, 2011.

MAGUIRE, J. D. Speed of germination-aid selection and evaluation for seedling emergence and vigor. Crop Science, Madison, v. 2, n. 3, p. 176-177, 1962.

MAURI, J.; LOPES, J. C.; FERREIRA, A.; AMARAL, J. F. T.; FREITAS, A. R. Germinação de sementes e desenvolvimento inicial da plântula de brócolos em função de substratos e temperaturas. Scientia Agraria, Curitiba, v. 11, v.4, p. 275-280, 2010.

PILAU, F. G.; SOMAVILLA, L.; BATTISTI, R.; SCHWERZ, L.; ULCZYNSKI, S. M. (2012) Germinação de sementes de crambe em diferentes temperaturas e substratos. Semina: Ciências Agrárias, Londrina, v. 33, n. 5, p. 1825-1830, 2012.

PINTO, J. R. S.; DOMBROSKI, J. L. D.; SANTOS JUNIOR, J. H.; SOUZA, G. O.; FREITAS, R. M. O. Growth of Mimosa caesalpiniifolia Benth., under shade in the northeast semi-arid region of Brazil. Revista Caatinga, Mossoró, v. 29, n. 2, p. 384-392, 2016.

REGHIN, M. Y.; OTTO, R. F.; VINNE, J. V. D. Tamanho da célula de diferentes bandejas na produção de mudas e no cultivo do Pak Choi na presença e na ausência do agrotêxtil. Scientia Agraria, Curitiba, v. 4, n.1, p. 6167, 2003.

SANTOS, L. L.; SEABRA JUNIOR, S.; NUNES, M. C. M. Luminosidade, temperatura do ar e do solo em ambientes de cultivo protegido. Revista de Ciências AgroAmbientais, Alta Floresta, v.8, n.1, p.83- 93, 2010.

SILVA, S. S.; ARAÚJO NETO, S. E.; KUSDRA, J. F.; FERREIRA, R. L. F. Produção orgânica de mudas de couve-manteiga em substratos à base de coprólito de minhocas. Revista Caatinga, Mossoró, vol. 20, n. 4, p. 78-83, 2007.

SOUZA, J. L.; RESENDE, P. Manual de Horticultura Orgânica. 3. ed. Viçosa: Aprenda Fácil, 2011. 843p.

STEINER, F.; PINTO JUNIOR, A. S.; DRANSKI, J. A. L.; ZOZ, T.; RHEINHEIMER, A.R. Germinação de sementes de rúcula sob diferentes temperaturas. Scientia Agraria, Curitiba, v. 11, n. 2, p. 119-124, 2010.

TESSARO, D.; MATTER, J. M.; KUEZMAN, O.; FURTADO, L.; COSTA, L.A.M. \& COSTA, M.S.S.M. Produção agroecológica de mudas e desenvolvimento a campo de couve-chinesa. Ciência Rural, Santa Maria, v. 43, n. 5, p. 831-837, 2013. 